\title{
Infecção hospitalar: métodos de avaliação das medidas econômicas referentes ao tratamento e a prevenção
}

Recebido: 28 jan 2019 Aceito: 10 fev 2019

Autor de correspondência: vivi.danelon@hotmail.com

Conflito de interesses: Os autores declaram não haver nenhum interesse profissional ou pessoal que possa gerar conflito de interesses em relação a este manuscrito.

\begin{abstract}
Viviane Daneleon NEVES ${ }^{(1)}$ Jaqueline Vilela BULGARELI ${ }^{(1)}$

Leonardo CARNUT ${ }^{(1)}$
\end{abstract}

${ }^{(1)}$ Faculdade de Saúde Pública, Universidade de São Paulo - USP, São Paulo, SP, Brasil.

\section{Resumo}

Infecções Relacionadas à Assistência à Saúde - IRAS, também chamadas de Infecções nosocomiais ou Infecções hospitalares, são definidas como infecções adquiridas por pacientes durante o tratamento em instituições de saúde, tendo sua origem a partir do momento da internação. Segundo a Organização Mundial da Saúde - OMS, estas infecções estão entre as maiores causas de morte e aumento de morbilidade entre os pacientes hospitalizados, levando a prejuízos sociais, econômicos e problemas de estruturação nas instituições de saúde. A morbidade e a mortalidade associadas às IRAS são significativas, resultando em menor qualidade de vida, hospitalizações mais longas e aproximadamente 99.000 mortes em excesso a cada ano. Nos Estados Unidos o ônus econômico das IRAS é estimado em US\$17 a US\$ 29 bilhões anualmente. Para os hospitais, os custos de IRAS também são reais e significativos, tornando a prevenção de IRAS um imperativo de gestão. Um estudo estimou esses custos médios em mais de US\$ 15,000 por IRAS, enquanto outro mostrou um intervalo entre US\$500 e US\$ 40,000 , dependendo do tipo de infecção. Os custos gerados pelas IRAS podem ser divididos em custos diretos, custos indiretos e custos intangíveis. Estes custos têm um impacto amplo dentro da cadeia de saúde, entre os agentes sujeitos aos prejuízos associados às IRAS, estão os pacientes, os familiares, os profissionais de saúde, as empresas, os hospitais e os planos de saúde, sendo que os danos podem ser financeiros e/ou mesmo psicológicos. Dentre os custos diretos temos o aumento do tempo de internação, aumento na demora para atendimento de outros pacientes, bloqueio de leitos, gastos adicionais com antibióticos, gasto com antibióticos mais potentes e mais caros, consultas, uso de equipamentos/tecnologias, equipe de saúde em geral, custo com desinfecção/descontaminação, gasto com testes laboratoriais, culturas, radiografias e antibiogramas, custo de oportunidade de atender novos pacientes, processos judiciais e indenizações financeiras. Já nos custos indiretos observa-se a diminuição da produtividade no trabalho em decorrência de sequelas, descontinuidade no trabalho relacionadas a morte de paciente por IRAS, perda de renda por membro da família, aumento da morbidade, mortalidade, tempo gasto por família e amigos para visitas hospitalares e custo de viagens. Em relação aos custos intangíveis destacam-se alterações emocionais e psicológicas, dor e imagem negativa para o hospital. Pode-se caracterizar três grandes 
impactos econômicos causados pelas IRAS em hospitais: custo de publicidade gerado pelo óbito de pacientes, implicando em custos sociais; custo econômico e financeiro, principalmente para hospitais públicos e filantrópicos que atendem pelo Sistema Único de Saúde - SUS, gerado pelo prolongamento no tratamento de pacientes (devido a internação); custo de oportunidade para os hospitais privados (ou filantrópicos com atendimento privado) gerados pela diminuição na rotatividade de pacientes, os quais apresentam maior rentabilidade nos primeiros dias de tratamento. Algumas políticas econômicas foram desenvolvidas com o intuito de diminuir substancialmente os gastos envolvidos com as IRAS. Muitos pesquisadores têm estudado de maneira focada o fenômeno financeiro em determina dos grupos atingidos pelas IRAS. A pesquisa pretende analisar os critérios econômicos estudados por esses autores nos períodos antes, durante e depois da internação dos pacientes que se enquadraram nas infecções hospitalares. Objetivo: o objetivo deste estudo de revisão é analisar as medidas econômicas adotadas que visam diminuir os custos e as despesas decorrentes das infecções hospitalares adquiridas durante o período de internação assim como os instrumentos adotados por essas políticas em relação a eficácia nas entidades hospitalares. Método: o estudo é baseado na revisão Integrativa para a coleta sistemática dos dados, relacionados aos custos com tratamento das infecções hospitalares levantando a produção científica disponível através da busca sistematizada em plataforma de bases de dados da Saúde. A busca sistematizada dos artigos foi realizada na plataforma da Biblioteca Virtual de Saúde - BVS (http://bvsalud.org/), considerando a técnica de funil na combinação dos descritores relacionados ao tema e separados nos grupos "contexto", "fenômeno" e "população". Foram utilizados os termos: "Gastos em Saúde", "Controle de Infecções" e Serviços em Saúde"; "Economia Hospitalar", "Controle de Custos" e "Entidade Hospitalar"; "Custos de Internação", "Infecção hospitalar" e "Convênios". A revisão percorreu as seguintes etapas: escolha do tema e formulação da hipótese de pesquisa; estabelecimento de critérios para inclusão e exclusão de estudos; busca sistemática e avaliação preliminar dos estudos encontrados. Resultados: Após as buscas, foram encontrados 21 artigos relacionados ao tema. Entretanto, apenas 16 apresentam-se mais restritos ao objetivo. Nesses artigos, as infecções hospitalares abordadas eram distintas entre um e outro, mas as medidas de prevenção e regulação dos gastos adotados eram semelhantes. Os artigos relacionados são de nacionalidade estrangeira (americana). Considerações finais: as sintaxes realizadas foram (mh:(( mh:("Gastos em Saúde" )) $O R$ (mh:( "Controle de Custos" )) $O R$ (mh:("Controle de Custos" )) OR (mh:("Custos de Internação")) $O R$ (mh:("Gastos em Saúde")) $O R$ (mh: ( "Controle de Infecções")) $O R$ (mh:( "Gastos em Saúde")) $O R$ (mh: ( "Economia Hospitalar")) $O R$ (mh:( "Controle de Custos")) $O R$ (mh: ("Controle de Infecções")) $O R$ (mh:("Controle de Custos")) OR (mh: ("Economia Hospitalar"))).

Descritores: Gastos em Saúde; Controle de Infecções; Economia Hospitalar; Controle de Custos; Infecção Hospitalar. 